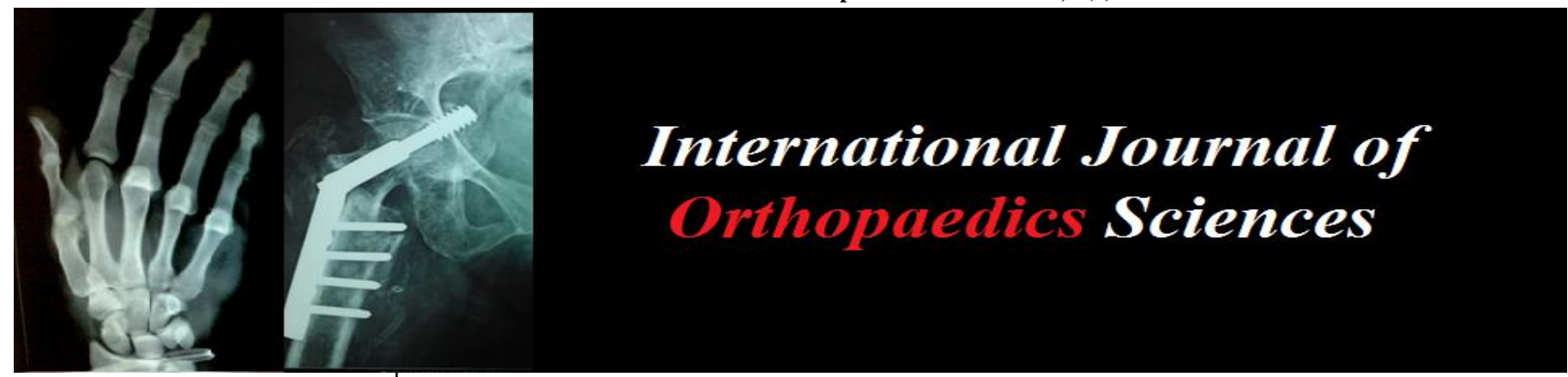

E-ISSN: 2395-1958

P-ISSN: 2706-6630

IJOS 2020; 6(3): 437-442

(C) 2020 IJOS

www.orthopaper.com

Received: 23-05-2019

Accepted: 25-06-2019

Dr. M Vijayashankar Associate Professor, Department of Orthopedics, Tagore Medical College, Tamil Nadu, India

Dr. Naveen Lysander Assistant Professor, Department of Orthopedics, Tagore Medical College, Tamil Nadu, India

Dr. Kathirazhagan S

Senior Resident Department of Orthopedics, Kauvery Hospitals, Chennai, India

Corresponding Author: Dr. Naveen Lysander Assistant Professor, Department of Orthopedics, Tagore Medical College, Tamil Nadu, India

\section{Outcome analysis of closed ankle fractures treated by ORIF}

\section{Dr. M Vijayashankar, Dr. Naveen Lysander and Dr. Kathirazhagan S}

DOI: https://doi.org/10.22271/ortho.2020.v6.i3g.2236

Abstract

Though malleolar fractures are discussed extensively, the opinions in the treatment of these fractures varies widely because of differences in classification reduction techniques and subjective symptoms at follow up studies. The primary goal of treatment should be full restoration of anatomy and function of the ankle joint. In this study we report clinically and radiologically the outcome of various types of ankle injury and to analyze the results of closed bimalleolar ankle fractures treated with open reduction and internal fixation.

Keywords: Ankle fractures, open reduction and internal fixation

\section{Introduction}

The ankle injuries gained importance because body weight is transmitted though it and the locomotion depends upon the stability of this joint. It must be realized that ankle injuries are mixed ones, ligamentous and body failures due to deforming forces. Bohler in 1929 discussed the importance of accurate reduction and possible joint motion. Many of these fractures were managed by manipulative reduction and conservative treatment and have yielded satisfactory results. Injuries like unstable syndesmotic diastasis, tri or bimalleolar fractures required open reduction and fixation. In this study we evaluated clinically and radiologically the type of injury and to analyze the results of closed bimalleolar ankle fractures treated with open reduction and internal fixation.

\section{AIM of the Study}

To evaluate clinically and radiologically the type of injury and to analyze the results of closed bimalleolar ankle fractures treated with open reduction and internal fixation.

\section{Materials and Methods}

This is prospective study done at Sri Ramachandra University, Chennai between April 2012October 2013 to assess the functional and radiological outcome of closed bimalleolar ankle fractures treated by open reduction and internal fixation. The duration of study was 18 months with a minimum follow up of 3 months to a maximum of 18 months. (Avg-12 months)

Total number of Patients assessed and evaluated in this study-30

\section{Method of Selection}

Inclusion Criteria

i) Closed ankle fractures in adults.

ii) Associated with subluxation \& dislocation of the ankle joint.

\section{Exclusion Criteria}

i) Open fractures.

ii) Talar fractures.

iii) Associated fractures of ipsilateral limb.

iv) Pilon fractures.

v) Children below 18 yrs. 
vi) Pathological fractures.

All patients were evaluated pre-operatively by clinical examination of the fracture site and radiologically using the Lauge-Hansen classification.

\section{Preoperative Protocol}

Displaced, malleolar fractures often involve significant subluxation or dislocation of the tibiotalar joint. To minimize pain, swelling and local trauma, such injuries were treated initially with analgesics, closed reduction and immobilization using a below knee slab. This was followed by limb elevation using pillows to reduce swelling. Prompt closed reduction of the ankle mortise decreases articular damage and in turn decreases soft tissue swelling.

Operative treatment was usually delayed for a few days till the initial swelling had subsided.

If soft tissue injury like abrasions and lacerations or blisters were present, surgery was delayed until the skin had healed. This was to minimize risk of infection post operatively.

Patients were operated immediately only if the patient presented immediately after injury and if skin over fracture site was healthy, provided general condition of the patient was stable.

\section{Operative Protocol}

All Patients were operated under spinal or general anesthesia in a supine position with tourniquet control and using image intensifier.

The implants used were $3,5 \mathrm{~mm}$ reconstruction plate, one third tubular plate, kirschner wire, 3.5mm DCP, LCP and tension band wiring for the fibula. Tension band wiring, locked compression plates and $4 \mathrm{~mm}$ partially threaded cancellous screws were used for the medical malleolus. And for the posterior malleolus, a $4 \mathrm{~mm}$ cannulated partially threaded cancellous screw with or without washer was used. A single $3.5 \mathrm{~mm}$ cortical screw was used in fixing of syndesmotic joint. Implants were selected based on the fracture pattern, quality of the bone and surrounding soft tissue.

\section{Post-operative Protocol}

- IV antibiotics for 3 days.

- This was followed with oral antibiotics till suture removal.

- $1^{\text {st }}$ wound inspection on second post- operative day.

- Check x-ray taken.

- Suture removal on $12^{\text {th }}$ day.

- Non-Weight bearing mobilization started from $3^{\text {rd }}$ postoperative day and active ankle mobilization exercises started.

- Non-Weight bearing mobilization continued for 6 weeks.

- Partial weight bearing after 6 weeks till 12 weeks, depending on fracture pattern and comorbidities.

- Full weight bearing walking started after 8 or 12 weeks, depending on fracture pattern, fixation and patient tolerance.

- Patient with syndesmotic injuries were generally kept nonweight bearing for 6 to 8 weeks.

- Syndesmotic screws were not removed before the start of weight bearing.

\section{Post-operative Evaluation}

Patients were followed clinically and radiologically evaluated at 6 weeks. 12 weeks, 24 weeks and thereafter, every year. Post-Operative evaluation of function and radiological outcome was done using the Baird and Jackson scoring system. This score is based on the criteria of pain, stability of ankle, ability to walk, run and do work, ankle movements and radiological analysis.

\section{Results}

Based on the Baird and Jackson scoring system, we graded our results as Excellent, Good, Fair and Poor. Our results were,

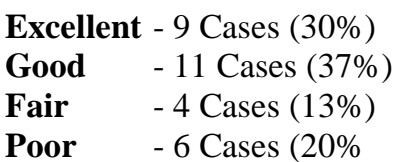

The study shows excellent and good results of $67 \%$ cases), with a poor result in $20 \%$ (6cases)

As per this study, my results showed the following

Gender: This study shows a male predominance of $64 \%$ (19) over a female percentage of 36(11).

Age: In our study, the mean age group falls in the middle age (43yrs), with more number of patients between 30 and 50 yrs of age.

Side: In our study, there is a right sided predominance of the fracture.

Mode of Injury: Our study shows that slip and fall, accounting to $53 \%$ of the total number of cases, is the most common cause for injury, followed by road traffic accidents

\section{Mechanism of Injury/Fracture Pattern}

In our study, Supination External Rotation (SER) mode of injury is the commonest fracture pattern with $33 \%$ of total cases and Supination Adduction as the rarer presentation in $17 \%$ of the cases.

\section{Duration between injury and presentation}

Most of the cases in this study presented to the hospital almost immediately following trauma, accounting to $83 \%$, with $10 \%$ of the cases presenting late.

\section{Time interval between injury and surgery}

In our study, there is a delay of 2-7 days for surgical treatment for most cases. Depending on various criteria like patients general condition, comorbidities, soft tissue condition at fracture site, etc. surgery was done within 48 hours of trauma or delayed.

\section{Effect of delay}

We attempted to analyze the relationship between the time period between time of injury and time of surgery and its influences on the end result.

i) Within 48 hours of trauma

Table 1: Surgery Within $48 \mathrm{hrs}$ of trauma and outcome

\begin{tabular}{|c|c|c|}
\hline Results & No. Of Patients & Percentage \\
\hline Excellent & 4 & $13 \%$ \\
\hline Good & 2 & $7 \%$ \\
\hline Fair & 1 & $3 \%$ \\
\hline Poor & 2 & $7 \%$ \\
\hline
\end{tabular}


ii) Between 2 to 7 days

Table 2: Surgery between 2 to 7 days of trauma and outcome

\begin{tabular}{|c|c|c|}
\hline Results & No. Of Patients & Percentage \\
\hline Excellent & 4 & $13 \%$ \\
\hline Good & 6 & $20 \%$ \\
\hline Fair & 2 & $7 \%$ \\
\hline Poor & 1 & $3 \%$ \\
\hline
\end{tabular}

iii) More than 7 days

Table 3: Surgery after 7 days of trauma and outcome

\begin{tabular}{|c|c|c|}
\hline Results & No. of Patients & Percentage \\
\hline Excellent & 1 & $3 \%$ \\
\hline Good & 2 & $7 \%$ \\
\hline Fair & 2 & $7 \%$ \\
\hline Poor & 3 & $10 \%$ \\
\hline
\end{tabular}

This clearly showed that when surgery was done within the first week following trauma, patients had a superior end functional and radiological result when compared with patients who were operated after 1 week.

\section{Tourniquet}

A tourniquet was always used to prevent blood loss and for a clear blood less field of surgery.

\section{Method of fixation of medial malleolar fractures}

After open reduction, the medial malleolus was fixed using an implant based on type of fracture and the soft tissue condition.

Table 4: Method of fixation of medial malleolar fractures

\begin{tabular}{|c|c|c|}
\hline Method of fixation & Number of patients & Percentage \\
\hline Cancellous screws alone & 17 & $57 \%$ \\
\hline Tension band wiring & 8 & $27 \%$ \\
\hline K-Wire +cancellous screw & 1 & $3 \%$ \\
\hline Plating & 3 & $10 \%$ \\
\hline POP stabilization post op & 1 & $3 \%$ \\
\hline
\end{tabular}

Maximum medial malleoli fixations done using cancellous screws alone $(57 \%)$ and tension band wiring (27\%).

\section{Method of fixation of lateral malleolar fractures}

After open reduction, the Lateral malleolus was fixed using an implant based on type of fracture and the soft tissue condition.

Table 5: Method of fixation of lateral malleolar fractures

\begin{tabular}{|c|c|c|}
\hline Method Of Fixation & Number Of Patients & Percentage \\
\hline Plating & 25 & $84 \%$ \\
\hline Tension band wiring & 3 & $10 \%$ \\
\hline K-Wire & 1 & $3 \%$ \\
\hline POP Stabilization Post Op & 1 & $3 \%$ \\
\hline
\end{tabular}

Maximum lateral malleoli fracture fixations done using plate fixation $(84 \%)$. Fewer cases were fixed with tension band wiring and K-Wire. One case was left unfixed and was immobilized using a below knee POP slab for 3 weeks.

Associated fracture fixation

Table 6: Associated fracture fixation

\begin{tabular}{|c|c|c|c|}
\hline Other fractures & Number of patients & Method of fixation & Percentage \\
\hline Syndesmotic disruption & 3 & $3.5 \mathrm{~mm}$ cortical screw & $10 \%$ \\
\hline Posterior malleolus & 2 & $\begin{array}{c}4 \mathrm{~mm} \text { partially threaded cannulated } \\
\text { cancellous screw }\end{array}$ & $6 \%$ \\
\hline
\end{tabular}

A syndesmotic screw was needed to stabilize the syndesmotic joint for 3 cases. Posterior malleolus needed operative fixation in 2 cases.

\section{Complications}

The complications seen post operatively are listed here

Table 7: Complications

\begin{tabular}{|c|c|c|}
\hline Complication & Number of Cases & Percentage \\
\hline Infection & 1 & $3 \%$ \\
\hline Malunion & 2 & $6 \%$ \\
\hline Wound dehiscence & 1 & $3 \%$ \\
\hline Delayed union & 1 & $3 \%$ \\
\hline Nonunion & 1 & $3 \%$ \\
\hline No complications & 24 & $82 \%$ \\
\hline
\end{tabular}

We had our fair share of complications with 1 case of infection, 2 cases of malunion, 1 nonunion, 1 case with delayed union and 1 case with wound dehiscence with infection.

Case reference

Type - Supination External Rotation Fracture

Baird and Jackson Score- 91

\section{ROM}

Dorsiflexion - 25 Degrees

Plantar flexion - 45 degrees

Result - Good

Duration Btw trauma and surgery - 3 Days

Comorbidities - None 


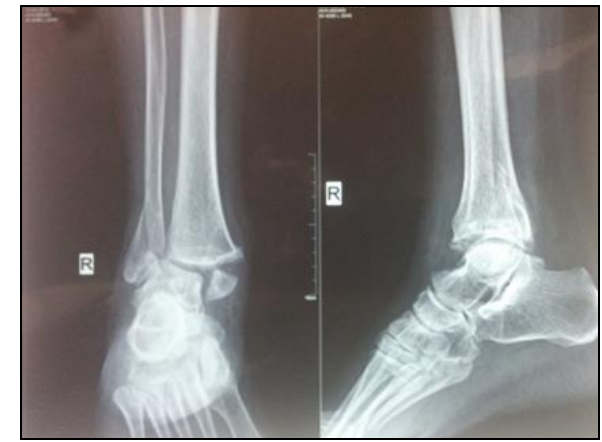

Pre OP

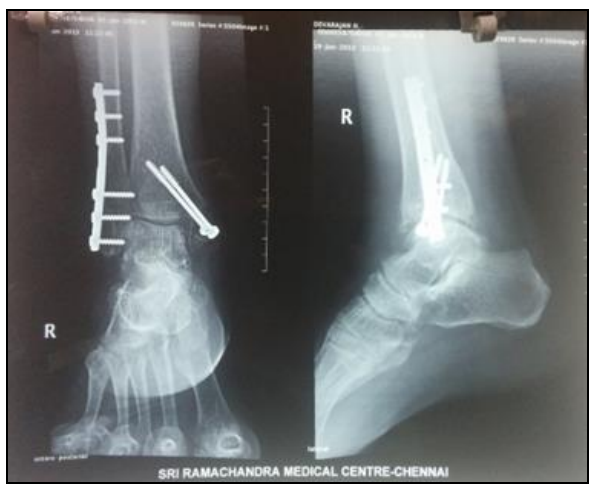

6 Months post op

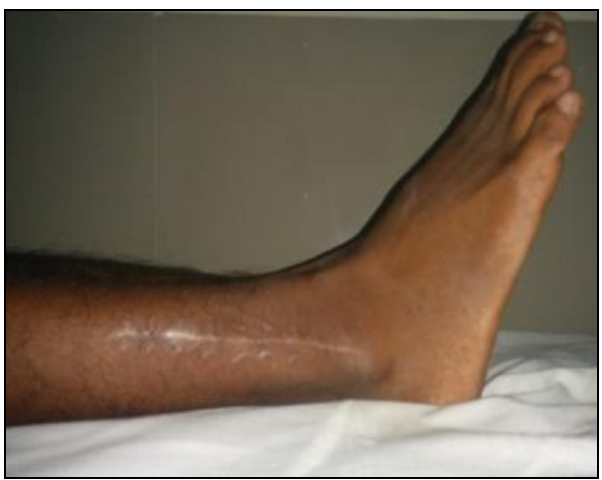

Neutral position

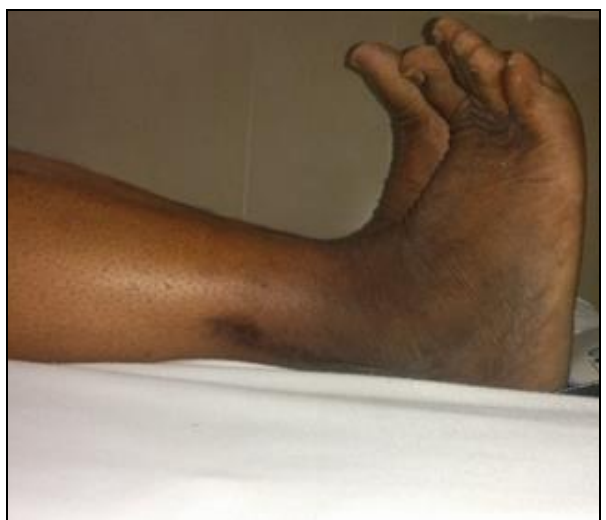

Bilateral Dorsiflexion

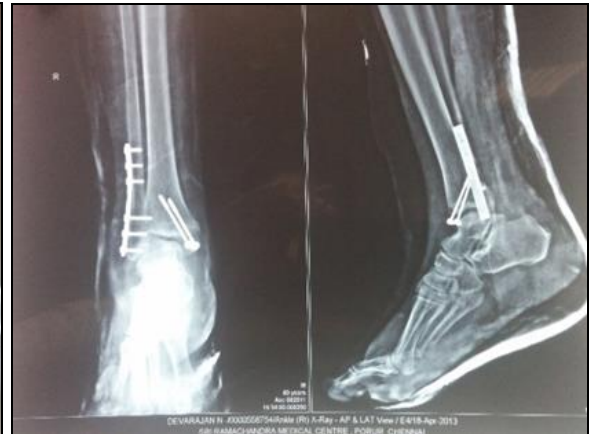

Post OP

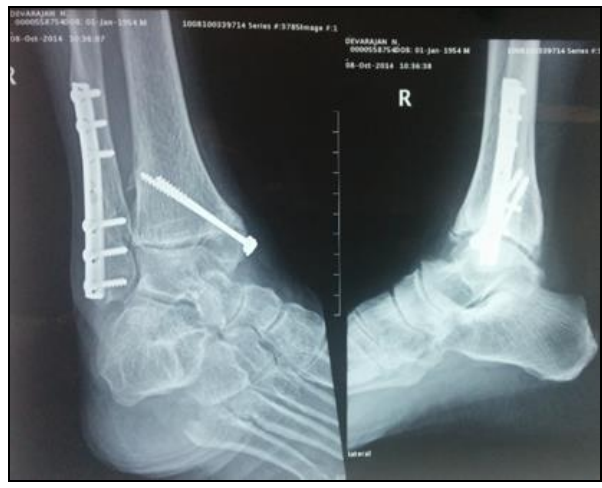

1 year post op

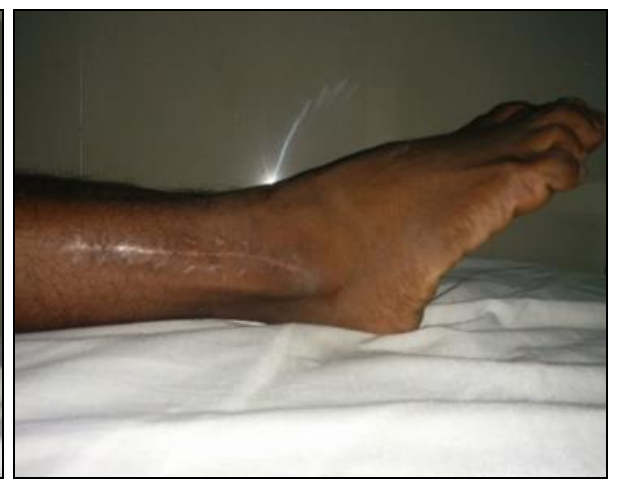

Bilateral Plantar Flexion

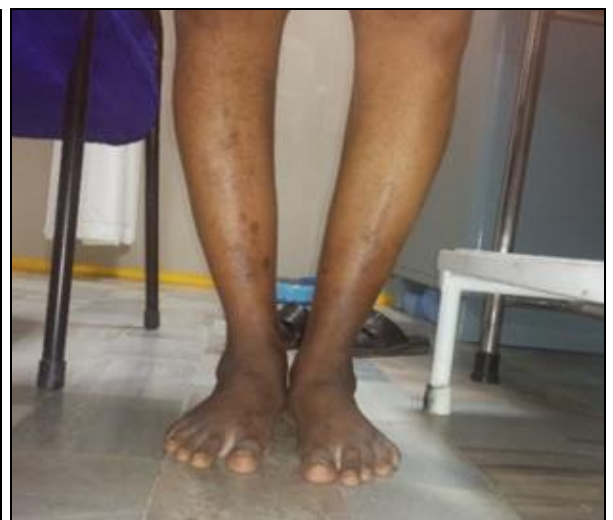

Standing

Fig: Case Reference

\section{Discussion}

Ankle fractures are the most common fractures of the lower extremity. They usually occur following a twisting injury following a fall (53\%) or a road traffic accident (37). This is a prospective study done to evaluate the functional and radiological outcome of closed Ankle fractures treated by Open Reduction and Internal Fixation and were analyzed results based on the BAIRD AND JACKSON SCORING 
SYSTEM. Patients with closed ankle fractures with or without subluxation were included in the study. Patients with Open fractures, Talar fractures, Pilon fractures, Non-unions and Malunions were not included in our study. All Patients were evaluated pre-operatively by clinical and radiological methods. The Fracture patterns were classified by the mechanism of injury described by Lauge-Hansen. Our study showed a predominance of Supination-External Rotation injuries $(33 \%)$ followed by Pronation-External Rotation $(27 \%)$, Pronation-Abduction (23\%) and $17 \%$ of supinationadduction injury. We had similar results comparing this study to those done by others,

Table 8: Distribution of fracture types in various studies

\begin{tabular}{|c|c|c|c|c|c|}
\hline Fracture type & Lindsjo n:611 & Lauge n:229 & Kristensen n:232 & Denham n:70 & Our Study \\
\hline Supination abduction & 20 & 16 & 16 & 10 & 5 \\
\hline Pronation abduction & 17 & 5 & 16 & 29 & 7 \\
\hline Supination external rotation & 42 & 71 & 45 & 49 & 10 \\
\hline Pronation external rotation & 13 & 7 & 22 & 9 & 8 \\
\hline Others & 8 & 1 & 1 & 3 & None \\
\hline
\end{tabular}

In our study we had a male predominance $(64 \%)$ which was similar when compared to the Olerud-Molander study.

We had patients age group fall between 18-80 years with mean age group of 43 yrs, with ankle fractures seem more commonly in the middle age groups. Twelve out of 30 patients were operated $(30 \%)$ within 48 hours and 13 cases (43\%) between 2-7days and 8 cases $(27 \%)$ more than 7 days. The delay in surgery for 8 cases were late arrival, treated with native splinting initially, co-morbid conditions like Diabetes, Ischemic heart disease, and Swelling following native treatment and poor skin conditions. Carragee et al. recommended early operative intervention for high-energy ankle fractures as a higher soft tissue complication rate was seen even for a delay of greater than 24 hours ${ }^{[11]}$.

Out of 30 patients, 25 cases of fibula were fixed with plating, 3 cases were fixed with tension band wiring, 1 case with Kwire and one left for conservative management. Nine cases of medial malleoli were fixed with Tension band wiring, 18 cases were fixed with cancellous screw fixation and 2 with plating. Two cases of posterior malleoli fractures were fixed with $4 \mathrm{~mm}$ partially threaded cancellous screws. Most authors agree that fixation of the posterior malleolus should be undertaken when $25 \%$ to $30 \%$ of the joint is involved. Syndesmotic screw fixation was needed in 3 cases done with $4 \mathrm{~mm}$ partially threaded cancellous screws.

Our patients were mobilized with syndesmotic screws insitu. Although screw removal at 6 to 8 weeks is advised by several authors, recent studies practice leaving it insitu. Ajay Manjoo et al and MD, David W. Sanders state that removal of syndesmotic screws after 6 months is advisable as it negates late syndesmotic displacement ${ }^{[37]}$.

Table 9: Comparison of various study outcomes

\begin{tabular}{|c|c|c|c|}
\hline Series & Number of cases & Excellent and good & Poor \\
\hline Gallent Series & 130 cases & $78 \%$ & $22 \%$ \\
\hline Frieberg Series & 105 cases & $85 \%$ & $15 \%$ \\
\hline Listeal Series & 212 cases & $78 \%$ & $22 \%$ \\
\hline Our Series & 30 cases & $67 \%$ & $33 \%$ \\
\hline
\end{tabular}

We assessed all the patients using the Baird and Jackson scoring system. Based on the score, we graded the patients into Excellent, Good, Fair and Poor results. Based on this score, we had $67 \%$ Excellent to Good results, $13 \%$ Fair results and $20 \%$ poor results. Comparing to other studies on the same fractures,

Table 10: Results using other Scoring systems

\begin{tabular}{|c|c|c|}
\hline Study & Scoring & Result (Good/Excellent) \\
\hline Day et al & Phillips scoring & $52 \%$ \\
\hline Lash N & Olerud-Molander score & $77 \%$ \\
\hline
\end{tabular}

The study showed improved results in patients who underwent surgery within the first 48 hours (20\%) and between 2 to 7 days (33\%) as compared to those done after 2 days. This was comparable with published International literature. In the Mont Miller et al study, Journal Orthop trauma 1992, in a study of 80 cases they opined that those patients with a delay between injury and surgery greater than 7 days tended to have a poorer result ${ }^{[42]}$.

\section{Complications}

We had 6 cases with complications which were followed up. Wound infection was seen in one case $(3 \%)$, malunion in one case $(6 \%)$, wound dehiscence in one case $(3 \%)$ with $3 \%$ delayed union and $3 \%$ nonunion in this study, and this is related to the presence of comorbid conditions like diabetes mellitus, hypertension, etc. The study shows that there is a direct relationship between comorbidities and final scores in patients. Around $50 \%$ of the cases with comorbid conditions developed complications, whereas only $9 \%$ of the cases without any comorbidities developed complications. All cases with complications, developed a poor result.

This is similar to the results of Costigan et al. and Jones et al., who identified neuropathy and hypertension as the most important predictors of postoperative complications in diabetic patients with ankle fractures ${ }^{[14]}$.

The study had a malunion ratio of $6 \%$, which shows that soft tissue condition at time of surgery, and delay in surgery result in poorer results. Fogel et al. showed a higher rate of malreduction when surgical delay exceeded 1 week for ankle fractures ${ }^{[22]}$.

\section{Conclusions}

- Immediate open Reduction and Internal Fixation in ankle fractures yield good results in terms of anatomical reduction, stability and Post Op functional return.

- Supination External Rotation injury is the commonest mechanism of injury in our study.

- Patient operated early, only if soft tissue was good, in order to have good functional outcome in closed ankle fractures.

- Delay in surgery tended to give a poorer result.

- Good control of comorbidities decreased Post Op complications.

- Early return of ankle movements Post OP with proper rehabilitation improved functional outcome ${ }^{\mathbf{1 9}}$.

- After a year of surgery, most patients experience little or mild pain and have certain restrictions of functional activities.

- Patients who needed syndesmotic joint operative stabilization, had poorer outcomes at the end of one year 
as compared to those that needed fixation of only bimalleolar fractures.

\section{References}

1. Ahl T, Dalen N, Holmberg S et al. Early weight bearing.

2. Beris AE, Kabbani KT, Xenakis TA et al. Surgical treatment of malleolar fractures. A review of 144 patients. Clin Orthop Relat Res, 1997, 90-98.

3. Blotter RH, Connolly E, Wagan A, Chapman Mw. Actue complications in the operative treatment of isolated ankle fractures in patients with DM. Foot Ankle. Int. 1999; 20:687.

4. Pettrone FA, Gail M, Pee D, Fitzpatrick T, Van Herpe LB. Quantitative criteria for prediction of the results after displaced fracture of the ankle. J Bone Joint Surg Am. 1983; 65:667-77.

5. Bostman OM, Ankle fractures treated using biodegradable int. fixation. Clin. Orthop. 1989; 238:195.

6. Breederveld RS Van Straaten. Immediate (or) Delayed operative treatment of fractures of the ankle. Injury. 1988; 19:436.

7. Brodie. Iaod; Denham RA. Treatment of unstable ankle fractures. JBJS 56 B: 256, 1974.

8. Campbell Operative Orthopaedics.

9. Nilsson GM, Eneroth M, Ekdahl CS. The Swedish version of OMAS is a reliable and valid outcome measure for patients with ankle fractures. BMC musculoskeletal disorders. 2013; 14:109.

10. Colton CL. Watson-Jones fracture and joint injuries, Vol. II, $6^{\text {th }}$ Edition, $1104-1152,1992$.

11. Daly P, Fitzgerald R, Melton L, IIstrup D. Epidemiology of ankle fractures in Rochester, Minnesota. Acta Orthop Scand. 1987; 58:539.

12. Costigan W, Thordarson DB, Debnath UK. Operative management of ankle fractures in patients with diabetes mellitus. Foot Ankle Int. 2007; 28:32-37.

13. Day GA, Swanson CE, Hulcombe BG. Operative treatment of ankle fractures: a minimum ten-year followup. Foot Ankle Int. 2001; 22:102-106.

14. Denham RA. Internal fixation for stable Ankle fracture JBJS. 1964; 46B:206-211.

15. Denis R. The aims of internal fixation Clin. Orthop. 1979; 138:23-25

16. Fogel GR, Morrey BF. Delayed open reduction and fixation of ankle fractures. Clin Orthop Relat Res, 1987, 187-195.

17. Bartonicek J, Rammelt S, Tucek M, Nanka O. Posterior malleolar fractures of the ankle. Eur J Trauma Emerg Surg. 2015; 41(6):587-600.

18. Gallent S, Frieberg T, Listeal P, Operative treatment in Ankle fractures Clini orthop16:118-124, 1983.

19. Burwell HN, Charnley AD. The treatment of displaced fractures at the ankle by rigid internal fixation and early joint movement. J Bone Joint Surg Br. 1965; 47:634-60

20. Gray's Anatomy, 555, 1979.

21. Wilson FC JR, Skilbred LA. Long-term results in the treatment of displaced bimalleolar fractures. J Bone Joint Surg Am. 1966; 48:1065-78.

22. Harper MC. Ankle fracture classification system. Foot Ankle 1992; 13:404-407.

23. Lehtonen $H$, Järvinen TL, Honkonen S, Nyman M, Vihtonen K, Järvinen M. Use of a cast compared with a functional ankle brace after operative treatment of an ankle fracture. A prospective, randomized study. J Bone Joint Surg Am. 2003; 85:205-11.
24. Finsen V, Saetermo R, Kibsgaard L, Farran K, Engebretsen L, Bolz KD et al. Early postoperative weightbearing and muscle activity in patients who have a fracture of the ankle. J Bone Joint Surg Am. 1989; 71:23-7.

25. Burr DB, Frederickson RG, Pavlinch C, Sickles M, Burkart S. Intracast muscle stimulation prevents bone and cartilage deterioration in cast-immobilized rabbits. Clin Orthop Relat Res. 1984; (189):264-78.

26. Salter RB, Hamilton HW, Wedge JH, Tile M, Torode IP, O'Driscoll SW et al. Clinical application of basic research on continuous passive motion for disorders and injuries of synovial joints: a preliminary report of a feasibility study. J Orthop Res. 1984; 1:325-42.

27. Ahl T, Dalén N, Selvik G. Mobilization after operation of ankle fractures. Good results of early motion and weight bearing. Acta Orthop Scand. 1988; 59:302-6.

28. Egol KA, Dolan R, Koval KJ. Functional outcome of surgery for fractures of the ankle. A prospective, randomised comparison of management in a cast or a functional brace. J Bone Joint Surg Br. 2000; 82:246-9. 